\title{
Short Communication: Effect of Temporary Glycosuria on Molasses Consumption in Holstein Calves
}

\author{
C. S. Wilcox, ${ }^{*}$ M. M. Schutz, ${ }^{*}$ S. S. Donkin, ${ }^{*}$ D. C. Lay Jr., $†$ and S. D. Eichert ${ }^{1}$ \\ *Department of Animal Sciences, Purdue University, West Lafayette, IN 47907 \\ †Livestock Behavior Research Unit, USDA-ARS, West Lafayette, IN 47907
}

\begin{abstract}
This study was conducted to determine the effect of experimentally increased glucose demand on voluntary consumption of molasses by dairy calves. Three-weekold calves received $0.365 \mathrm{~g}$ of phlorizin by s.c. injection. Urinary output and molasses consumption were measured hourly, and urinary glucose concentration was screened. Molasses consumption for the $24 \mathrm{~h}$ after treatment was (mean $\pm \mathrm{SE}) 72.0 \mathrm{~g}( \pm 7)$ for the control group and $142 \mathrm{~g}( \pm 1)$ for the phlorizin-treated group. Urinary output for the 8 -h test period was $1.13 \mathrm{~kg}$ for the control group and $1.67 \mathrm{~kg}$ for the phlorizin-treated calves. Mean urinary glucose peaked at $10 \mathrm{~g} / \mathrm{L}$ by $4 \mathrm{~h}$ after treatment for calves given phlorizin, whereas the concentration for the control group remained close to 0 $\mathrm{g} / \mathrm{L}$. Phlorizin treatment increased voluntary consumption of molasses in 3-wk-old Holstein calves.
\end{abstract}

Key words: dairy calves, glycosuria, molasses, phlorizin

Glucose is the principal source of energy for the central nervous system and is essential in the synthesis of structural polysaccharides, glycoproteins, and glycolipids of cell membranes, and cartilage. Glucose metabolism in neonatal ruminants resembles that of nonruminants (Young et al., 1974; Baldwin et al., 2004). Homeostatic blood glucose concentration is maintained by renal tubular reabsorption of glucose from the urine before excretion as well as by hepatic gluconeogenesis (Oulianova et al., 2001). Hepatic gluconeogenesis in neonatal calves is inhibited primarily by insulin and is induced by glucagon (Donkin and Hammon, 2005) and glucocorticoids (Barthel and Schmoll, 2003).

Hypoglycemia in cattle is known to occur in cases of ketosis and fatty liver (Bobe et al., 2004). In humans, hypoglycemia commonly occurs because of adrenal fatigue. During stress, elevated circulating cortisol concentrations stimulate hepatic gluconeogenesis and

Received January 7, 2008.

Accepted May 1, 2008.

${ }^{1}$ Corresponding author: Susan.Eicher@ars.usda.gov reduce glucose uptake in muscle and adipose tissue (Simmons et al., 1984). In the case of adrenal fatigue, lower than expected cortisol concentrations decrease the normal hepatic response to glucose demand. Additionally, hypoglycemia in humans is known to cause sugar cravings (Wilson, 2001).

Stress causes an increase in hippocampal glucose demand (Fellows et al., 1993). However, in the rat and mice models, predatory stress, especially chronic stress, was associated with a decrease in sucrose intake (Calvo-Torrent et al., 1999). In other studies (Michaels and Holtzman, 2006), postnatal stress (maternal separation) was associated with an increase in sucrose consumption. The effects of stress on the consumption of sweeteners have not been determined for neonatal calves. Therefore, we investigated the effects of experimentally induced hypoglycemia in dairy calves on sucrose (molasses) intake.

Phlorizin, a glycoside from fruit trees, causes temporary glycosuria by blocking the renal tubular reabsorption of glucose (Oulianova et al., 2001) and thus increases the irreversible loss of glucose in the urine. Phlorizin treatment did not induce hyperphagia in mature dairy cows (Bradford and Allen, 2005) but increased glucose entry rates in sheep (Egan et al., 1983; Overton et al., 1998) and cattle (Veenhuizen et al., 1988). The objective of this study was to determine the effect of experimentally inducing an increase in glucose demand with phlorizin on the voluntary consumption of molasses by neonatal calves.

Twelve Holstein bull calves were housed in individual calf hutches with $0.84 \mathrm{~m}^{2}$ of fenced exercise area. All calves were fed a commercial milk replacer $(12.5 \% \mathrm{DM}$, $18 \%$ CP, $22 \%$ fat; Market Blend Pre-starter, Strauss Veal, Watertown, WI) divided into 2 equal feedings (4 $\mathrm{L} / \mathrm{d}$ ). Grain-based calf starter and forage were omitted from the feeding schedule to retard the development of rumen function. When the calves were $3 \mathrm{wk}$ old, they were given ad libitum access to liquid molasses (Evolved Habitats, New Roads, LA) in buckets for 6 d to allow for adaptation to the taste and placement of buckets. Molasses disappearance (consumption) was measured by weight every $24 \mathrm{~h}$. On d 7, the calves were randomly 


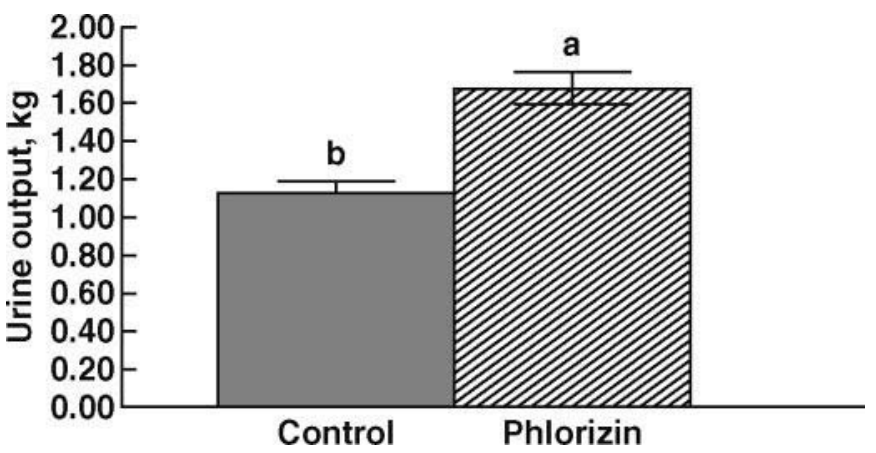

Figure 1. Mean urinary output $( \pm \mathrm{SE})$ of calves over the entire 8-h test for calves given phlorizin or normal saline by s.c. injection. ${ }^{\mathrm{a}, \mathrm{b}}$ Means with differing letters differ $(P=0.026 ; \mathrm{n}=6$ calves/treatment).

assigned to either a control group or a phlorizin treatment group. Calves in the control group received 3 $\mathrm{mL}$ of sterile saline and those in the phlorizin group received $0.365 \mathrm{~g}$ of phlorizin dihydrate (Sigma-Aldrich, St. Louis, MO) in $3 \mathrm{~mL}$ of sterile saline by s.c. injection. This study was approved by the Purdue Animal Care and Use Committee.

Absorbent pads (Johnson and Johnson, New Brunswick, NJ) were placed on the calves to collect urine and were secured with an elastic bandage (Vet Wrap, 3M, St. Paul, MN). Urinary glucose was determined hourly over an 8-h period from the weight of urine collected, and concentration of glucose in the urine was deter- mined by colorimetric urine-reagent test strips (LW Scientific Inc., Lawrenceville, GA).

At the end of the test period, treatment calves were killed by intravenous administration of $10 \mathrm{cc}$ of pentobarbital (Beuthanasia-D, Schering-Plough Animal Health Corporation, Summit, NJ) and exsanguination. Control animals were returned to the herd.

The data were tested for normality and nonconstant variance by using the univariate procedure of SAS (SAS Institute Inc., Cary, NC). All data conformed to the normality and constant variance assumption. The mixed-models procedure of SAS (SAS Institute Inc.) was used to analyze the effect of treatment on glucose concentration in the urine, urinary output, and molasses consumption. During the 8-h observation, mean hourly urinary output was (mean $\pm \mathrm{SE}) 1.13 \mathrm{~kg}( \pm 0.06)$ for control calves and $1.67 \mathrm{~kg}( \pm 0.08)$ for phlorizintreated calves (Figure 1). Mean urinary glucose concentration for control calves remained below $1 \mathrm{~g} / \mathrm{L}( \pm 0.25)$ during the entire 8 -h observation period, whereas the phlorizin-treated calves averaged $5 \mathrm{~g} / \mathrm{L}( \pm 0.00)$ for the first $2 \mathrm{~h}$, peaked at $8 \mathrm{~g} / \mathrm{L}( \pm 0.45)$ at $4 \mathrm{~h}$ posttreatment, and ended at $2.83 \mathrm{~g} / \mathrm{L}( \pm 0.51)$ at $8 \mathrm{~h}$ posttreatment (Figure 2). Baseline daily molasses consumption fluctuated between 70 and $100 \mathrm{~g} / \mathrm{d}( \pm 5 \mathrm{~g} / \mathrm{d})$ for both groups $(P=0$ 0.28 ). Molasses consumption for the $24 \mathrm{~h}$ after treatment was $72 \mathrm{~g}( \pm 7)$ for the control group and $142 \mathrm{~g}( \pm 1$; $P=0.02$ ) for the phlorizin-treated group (Figure 3).

Urinary glucose concentration increased with phlorizin treatment $(P<0.001)$, as did the urinary output

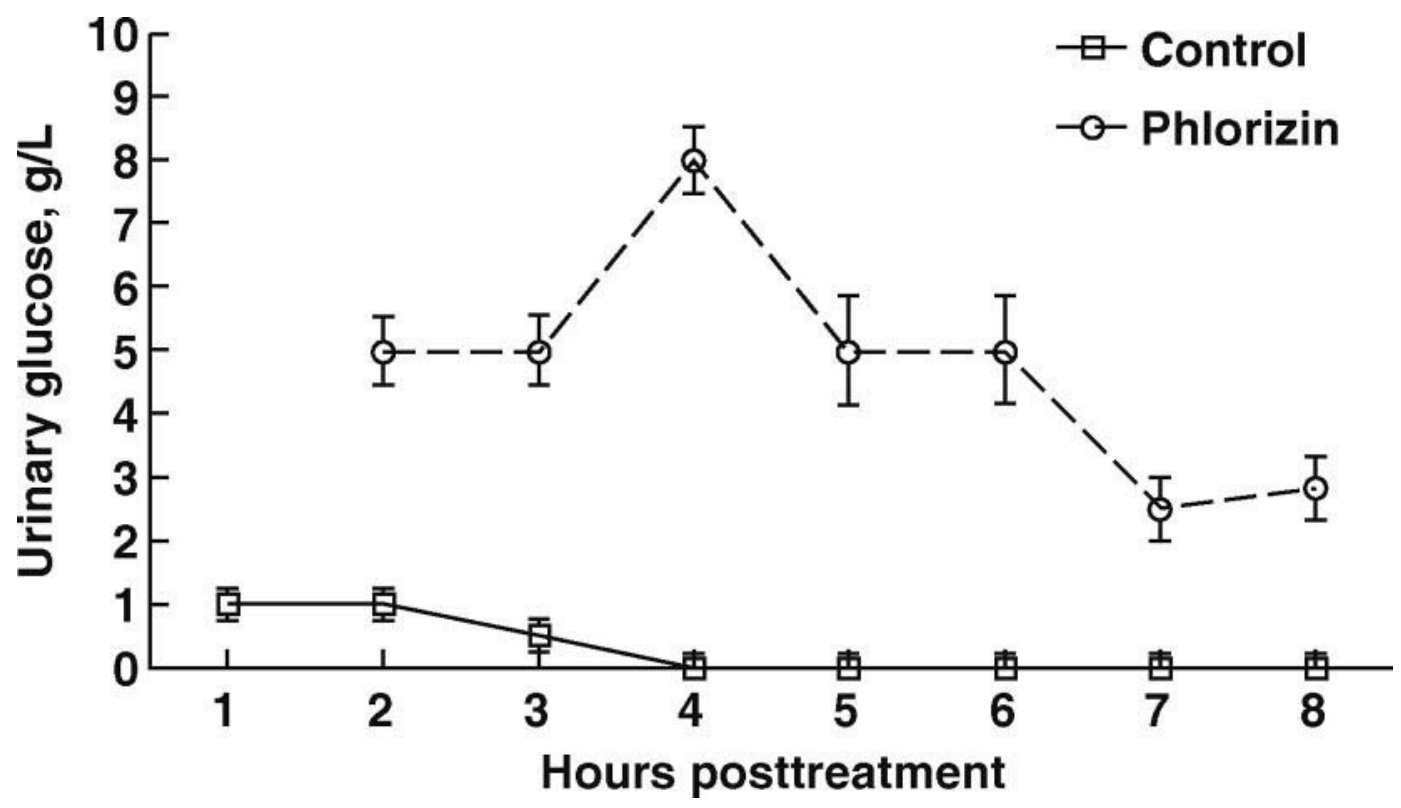

Figure 2. Mean urinary glucose concentration $( \pm \mathrm{SE})$ of 8 -h tests for calves given phlorizin or normal saline by s.c. injection. Phlorizintreated calves did not urinate during the first hour, as reflected by no 1-h data point. Urinary glucose of phlorizin-treated calves was greater than that of control calves for all other times after the baseline (treatment effect, $P=<0.001 ; \mathrm{n}=6$ calves/treatment). 


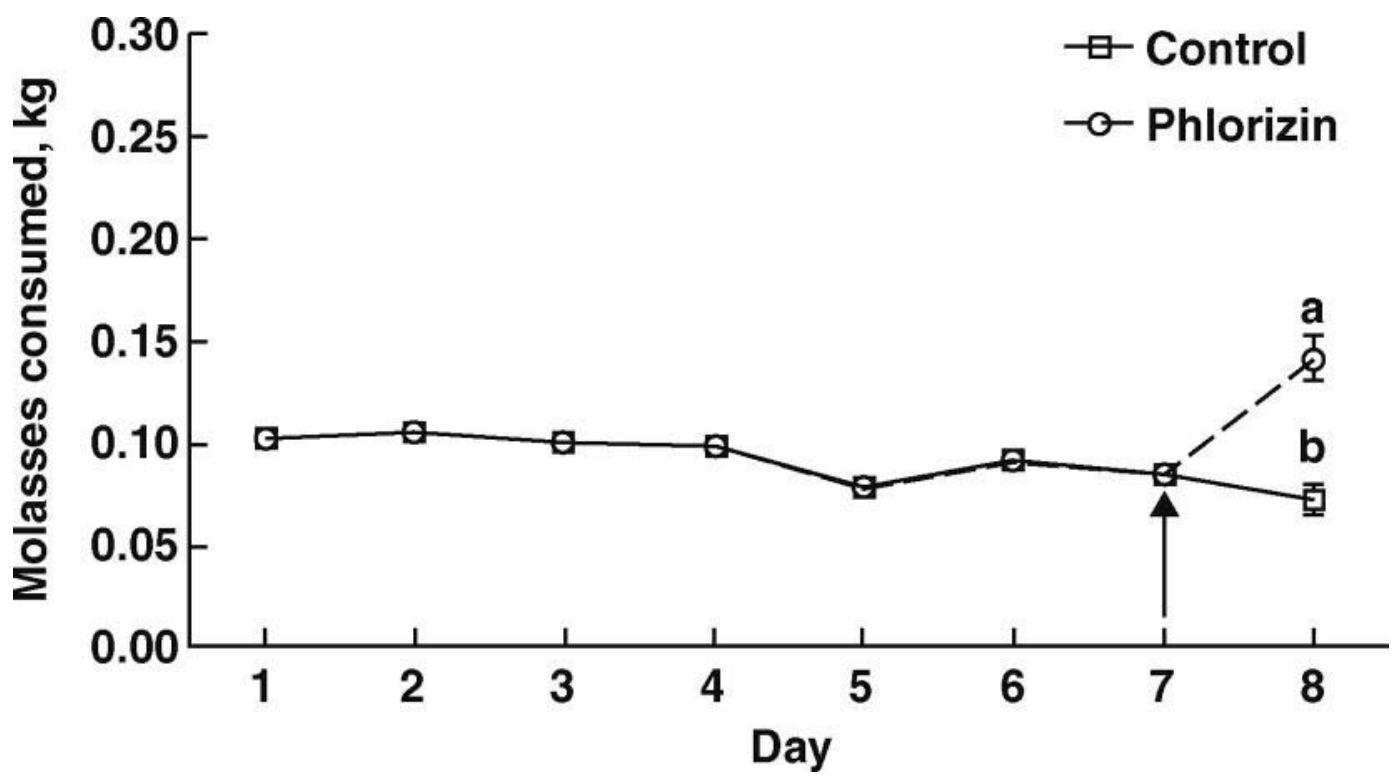

Figure 3. Mean daily molasses consumption ( \pm SE) of calves given phlorizin or normal saline by s.c. injection on $d 7$. Days 4 to 7 are baseline values. The arrow indicates injection on $\mathrm{d} 7$. Means within a time with differing superscripts differ, $P=0.02$ (pooled SE $=5 \mathrm{~g} / \mathrm{d}$ ).

$(P=0.026)$. This confirmed that phlorizin treatment of these calves resulted in glucosuria, thereby creating an increase in endogenous demand for glucose. Because the calves were healthy and homeostasis was expected to be maintained, blood glucose was not measured. These results are consistent with the results of previous studies. In a study conducted with Dorset wethers, Overton et al. (1998) found that increasing the dosage of phlorizin injected at 8-h intervals increased urine glucose concentrations. Likewise, when phlorizin was administered to adult dairy cows, glucose excretion in the urine increased (Bradford and Allen, 2005).

Molasses consumption increased $(P=0.02)$ in response to phlorizin treatment. In mice, physiological stress is known to cause a rapid increase in hippocampal nonoxidative glucose metabolism (Fellows et al., 1993). Restraint-stress studies in rats showed stress-related inhibition of cellular glucose transport and a resulting weight loss (Zhou et al., 2001). Chronic psychological stress in mice and rats has led to significant decreases and increases in sucrose intake, which are considered accurate indicators of stress (CalvoTorrent et al., 1999; Zhou et al., 2001). Results of our study showed that altering glucose metabolism by experimentally increasing urinary glucose losses led to increased voluntary sucrose intake. Other factors that alter glucose metabolism, such as elevated circulating cortisol concentrations found in states of stress, may possibly also change voluntary sucrose intake in dairy calves. These data are consistent with the previously observed increased sucrose intake in response to stress in nonruminants. Additional investigations are needed to confirm the relationship between stress and voluntary sucrose intake and to extend the utility of this feeding behavior response as an experimental model. However, this research suggests that molasses consumption may be useful as a noninvasive well-being measure of the increase in glucose demand created by stressors in neonatal calves.

\section{REFERENCES}

Baldwin, R. L., K. R. McLeod, J. L. Klotz, and R. N. Heitmann. 2004. Rumen development, intestinal growth and hepatic metabolism in the pre- and postweaning ruminant. J. Dairy Sci. 87(E Suppl.):E55-E65.

Barthel, A., and D. Schmoll. 2003. Novel concepts in insulin regulation of hepatic gluconeogenesis. Am. J. Physiol. Endocrinol. Metab. 285:E685-E692.

Bobe, G., J. W. Young, and D. C. Beitz. 2004. Invited review: Pathology, etiology, prevention, and treatment of fatty liver in dairy cows. J. Dairy Sci. 87:3105-3124.

Bradford, B. J., and M. S. Allen. 2005. Phlorizin administration increases hepatic gluconeogenic enzyme mRNA abundance but not feed intake in late-lactation dairy cows. J. Nutr. 135:22062211.

Calvo-Torrent, A., P. F. Brain, and M. Martinez. 1999. Effect of predatory stress on sucrose intake and behavior on the plusmaze in male mice. Physiol. Behav. 67:189-196.

Donkin, S. S., and H. M. Hammon. 2005. Hepatic gluconeogenesis in developing ruminants. Pages 375-390 in Biology of Metabolism in Growing Animals. D. G. Burrin and H. J. Mersmann, ed. Elsevier, Amsterdam, the Netherlands.

Egan, A. R., J. C. MacRae, and C. S. Lamb. 1983. Threonine metabolism in sheep. I. Threonine catabolism and gluconeogenesis in mature Blackface wethers given poor quality hill herbage. Br. J. Nutr. 49:373-383. 
Fellows, L. K., M. G. Boutelle, and M. Fillenz. 1993. Physiological stimulation increases nonoxidative glucose metabolism in the brain of the freely moving rat. J. Neurochem. 60:1258-1263.

Michaels, C. C., and S. G. Holtzman. 2006. Neonatal stress and litter composition alter sucrose intake in both rat dam and offspring. Physiol. Behav. 89:735-741.

Oulianova, N., S. Falk, and A. Berteloot. 2001. Two-step mechanism of phlorizin binding to the SGLT1 protein in the kidney. J. Membr. Biol. 1:223-242.

Overton, T. R., J. K. Drackley, C. J. Ottemann-Abbamonte, A. D. Beaulieu, and J. H. Clark. 1998. Metabolic adaptation to experimentally increased glucose demand in ruminants. J. Anim. Sci. 76:2938-2946.

Simmons, P. S., J. M. Miles, J. E. Gerich, and M. W. Haymond. 1984 Increased proteolysis. An effect of increases in plasma cortisol within the physiologic range. J. Clin. Invest. 73:412-420.
Veenhuizen, J. J., R. W. Russell, and J. W. Young. 1988. Kinetics of metabolism of glucose, propionate and $\mathrm{CO}_{2}$ in steers as affected by injecting phlorizin and feeding propionate. J. Nutr. 118:1366-1375.

Wilson, J. 2001. Adrenal Fatigue: The 21st Century Stress Syndrome. Smart Publications, Petaluma, CA.

Young, J. W., S. P. Schmidt, E. S. Akowuah, G. S. Hess, and A. D. McGilliard. 1974. Effects of phlorizin on glucose kinetics in the bovine. J. Dairy Sci. 57:689-694.

Zhou, J., M. X. Shi, T. D. Mitchell, G. N. Smagin, S. R. Thomas, D. H. Ryan, and R. B. S. Harris. 2001. Changes in rat adipocyte and liver glucose metabolism following repeated restraint stress. Exp. Biol. Med. (Maywood) 226:312-319. 